\title{
RESEÑA: CATHERINE MANSFIELD: EL POSMODERNISMO INCIPIENTE DE UNA MODERNISTA RENEGADA. GERARDO RODRÍGUEZ SALAS ${ }^{1}$
}

\author{
Laura Torres Zúñiga ${ }^{2}$
}

\begin{abstract}
Rodríguez Salas, G. 2009. Katherine Mansfield: El posmodernismo incipiente de una modernista renegada. Madrid: Verbum. 284 páginas. ISBN: 978-84-7962-456-9.
\end{abstract}

En su segunda monografía sobre Katherine Mansfield (tras Hijas de la Diosa Blanca: Ginocrítica y Feminismo Restaurador en la Narrativa de Katherine Mansfield, Septem, 2007), Gerardo Rodríguez Salas nos invita a un progresivo descubrimiento de las pinceladas posmodernas que esta narradora neozelandesa, categorizada habitualmente dentro del periodo de auge modernista, diseminó por sus relatos. Rodríguez Salas parte de un concepto de posmodernismo que trasciende los límites cronológicos que sitúan a este movimiento a mediados del siglo XX, entendiéndolo como un espíritu, unos valores que bien pudieron ser compartidos y vislumbrados por artistas de periodos anteriores. El autor estudia y agrupa los atributos literarios posmodernistas más relevantes en cuatro secciones donde inicialmente los define y debate, para, a continuación, analizar su presencia en una amplia selección de relatos de Mansfield.

Rodríguez Salas comienza rastreando la representación del sujeto escindido no sólo en la creación ficcional de Mansfield sino en la propia auto-percepción que ésta refleja a través de materiales autobiográficos como cartas y diarios. Aunque en las primeras la autora resulta relativamente convincente en su defensa de una esencia humana inmanente y alcanzable bajo la aparente confusión causada por las influencias sociales - lo que la acercaría al esencialismo modernista -, Rodríguez Salas nos muestra cómo en su diario y sus relatos Mansfield pone de manifiesto una concepción posmodernista del sujeto, concibiéndolo como una superposición de máscaras que ocultan un vacío existencial que, si bien puede llegar a ser desolador, también puede desvelar su positiva capacidad subversiva al efectuar el desmantelamiento o "desdogmatización" de la artificialidad del sistema (69). Así, el autor designa como "optimista" la posición posmodernista de Mansfield en su obra epistolar, mientras que su diario y la mayoría de sus relatos exponen una postura "conciliadora" que trata de aceptar la fragmentación y simulación del sujeto escindido combinadas con la intuición de una autenticidad humana, "lo sublime" posmodernista, que apenas

\footnotetext{
Fecha de recepción: junio 2009.

Fecha de aceptación y versión definitiva: junio 2009.

2 Contratada pre-doctoral, Departamento de Filologías Inglesa y Alemana, Universidad de Granada; $\square$ lzuniga@ugr.es.
} 
puede ser discernida en momentos visionarios que se frustran a causa de las "respuestas suspendidas" y el "bloqueo final" del código hermenéutico definido por Barthes (49). En "The Daughters of the Late Colonel" o "The Garden-Party", las protagonistas femeninas representan sujetos dialógicos divididos entre los roles sociales y los deseos personales, quienes sufren la imposibilidad de verbalizar la esencia de su propia existencia que tan cerca se encuentran de aprehender. Sólo en raras excepciones, como el relato "Je Ne Parle Pas Français", se destilan trazos de una visión "apocalíptica" en la que Mansfield exterioriza un escepticismo extremo acerca de la presencia de un fundamento humano innato antes del condicionamiento social (81).

La comprensión de la fragmentación del sujeto posmodernista va irremediablemente acompañada de la reflexión sobre el poder dogmático del lenguaje para crear aquellas máscaras que nos falsean una identidad que creemos propia y autónoma. Dado que el lenguaje es una herramienta de opresión más dentro de los aparatos ideológicos del estado patriarcal teorizados por Louis Althusser, el silencio con que Mansfield puntúa la expresión de sus personajes femeninos se satura de significados reivindicativos que debemos descifrar. Rodríguez Salas identifica un primer uso del silencio como reflejo de la aniquilación discursiva $-y$ por tanto, como sujetos - de estas mujeres, con el objetivo de provocar la reacción del público lector mediante la ironía dramática (104). Sin embargo, relatos como "The Doll's House" anuncian la posibilidad más optimista de una estrategia de expresión semiótica reservada a las mujeres, quienes gracias a un silencio cargado de connotaciones lograrían trascender la constricción y univocidad de un lenguaje sólo aparentemente inocente. La paraliterariedad, otra maniobra subversiva de la narrativa posmodernista para revelar la opresión ideológica por medio del lenguaje, también aparece de forma incipiente en Mansfield, en donde el autor detecta elementos paraliterarios que anticipan el Verfremdungseffekt brechtiano y el concepto de "metaficción historiográfica" de Linda Hutcheon. "Miss Brill" o "A Married Man's Story" nos presentan protagonistas, tanto femeninos como masculinos, que rompen los límites textuales para hacer hincapié en el mismo proceso literario a través del cual se perciben como actores y directores de una pantomima rutinaria que creen controlar pero que únicamente encubre las manipulaciones soterradas del sistema.

Continuando con la desmitificación del sistema lingüístico y literario, Rodríguez Salas centra las dos últimas secciones de su estudio en la utilización deliberada de la intertextualidad respecto a dos géneros literarios canónicos en su representación de la infancia y los roles de género: los cuentos de hadas y la novela sentimental. Mansfield "toma como hipogénero ... los cuentos tradicionales de Charles Perrault, Christian Andersen y los hermanos Grimm, los filtra mediante la sensibilidad decadente de Oscar Wilde y les atribuye, por último, la proyección paródica y crítica de los rusos", obteniendo con ello un hipertexto innovador y subversivo (144). En este proceso el autor distingue un diferente enfoque a lo largo de una división diacrónica de los relatos: mientras Mansfield comienza enfatizando el elemento mágico y realizando un pastiche de elementos constitutivos del género del cuento de hadas en sus composiciones tempranas, los relatos más maduros emanan una crítica social más directa y ácida por medio de parodias de cuentos particulares. Así, con los hermanos de "Sun and Moon" como una trasposición de "Hansel y Gretel" y la protagonista de "The Tiredness of Rosabel" como una Cenicienta contemporánea, Mansfield demuestra su capacidad de jugar con dos niveles de significación paralelos en un sutil ejercicio de 
heteroglosia entre esas voces marginales infantiles y femeninas y el discurso patriarcal dominante. De un modo similar, con su reutilización irónica de los clichés de la novela sentimental Mansfield nos hace evidente el carácter absurdo de la mentalidad romántica que han interiorizado las mujeres en "Taking the Veil", "Violet" y "Pictures", así como las consecuencias destructivas que ésta puede llegar a tener si no descubrimos a tiempo su efecto alienador. Valiéndose de la inversión de la catarsis purificadora en el desarrollo de lo que Rodríguez Salas clasifica como ironía "posmodernista" o "suspensiva" (266), la narradora consigue un efecto de pastiche de género de acuerdo con la definición de Gérard Genette y muestra su intención de "desmantelar la brecha entre el idealismo instigado en las mujeres [por la novela sentimental] y la sórdida realidad con la que finalmente han de enfrentarse" (249).

Rodríguez Salas defiende y justifica de forma convincente los rasgos posmodernistas que insinúa la narrativa de Katherine Mansfield, e insiste a lo largo de todo su trabajo en las tendencias fundamentales que diferencian a esta escritora de sus coetáneos modernistas: frente a la apolitización y el ahistoricismo del Modernismo, Mansfield pretende emplear la literatura como arma desdogmatizadora que denuncie la aparente naturalidad del patriarcado y despierte el espíritu rebelde en el público (79-80); ante el objetivo totalizador final en la búsqueda modernista de la esencia humana, su obra no intenta concretar el "sujeto alotrópico" que definió D.H. Lawrence, ni siquiera perseguir "lo sublime" hasta su manifestación epifánica, sino advertirnos del engaño, la artificialidad, pero también la plasticidad de nosotros mismos y del sistema para, optimista y consecuentemente, reconciliarnos con nuestra situación y movilizarnos en una acción social colectiva para mejorarla (265). A estos respectos, quizá se echa en falta una datación individual de la fecha de composición o publicación de las historias para ayudar al lector profano a apreciar lo innovador del talento de Mansfield en relación con su contexto histórico-literario inmediato.

Katherine Mansfield: El posmodernismo incipiente de una modernista renegada no es tan sólo un volumen imprescindible para aquel especialista en Katherine Mansfield que coincida con Patrick D. Morrow en que ya era preciso realizar un estudio de esta autora neozelandesa desde la perspectiva posmodernista (16), o que desee acercarse a uno de los escasos análisis críticos que revaloriza merecidamente su a menudo menospreciada juvenilia. La monografía de Rodríguez Salas logra además ejecutar un estudio profundo y perspicaz con tal claridad y minuciosidad que su detallada exposición de cuestiones posmodernistas y su esclarecimiento de términos de fácil confusión (la interrelación entre ironía, parodia y pastiche; la diferencia entre polifonía, dialogismo y heteroglosia, o el concepto de $c a$ tacresis, por mencionar algunos) la dotan de un carácter didáctico que la hace atractiva para cualquier investigador principiante. Ambos atributos convierten a este libro en una valiosa contribución tanto a la crítica mansfieldiana como a la literaria en general. 